

\title{
AN ATTEMPT TO IMAGE ORGANIC MOLECULES WITH FIM
}

F. Iwatsu, Naoto Morikawa, T. Terao

\section{To cite this version:}

F. Iwatsu, Naoto Morikawa, T. Terao. AN ATTEMPT TO IMAGE ORGANIC MOLECULES WITH FIM. Journal de Physique Colloques, 1987, 48 (C6), pp.C6-263-C6-268. 10.1051/jphyscol:1987643 . jpa-00226848

\section{HAL Id: jpa-00226848 https://hal.science/jpa-00226848}

Submitted on 1 Jan 1987

HAL is a multi-disciplinary open access archive for the deposit and dissemination of scientific research documents, whether they are published or not. The documents may come from teaching and research institutions in France or abroad, or from public or private research centers.
L'archive ouverte pluridisciplinaire HAL, est destinée au dépôt et à la diffusion de documents scientifiques de niveau recherche, publiés ou non, émanant des établissements d'enseignement et de recherche français ou étrangers, des laboratoires publics ou privés. 
AN ATTEMPT TO IMAGE ORGANIC MOLECULES WITH FIM

F. Iwatsu, H. Morikawa and T. Terao

Department of Materials Science and Engineering, Nagoya Institute of Technology, Gokiso-cho, Showa-ku, Nagoya 466, Japan

\section{Résumé}

Des molécules de phtalocyanine d'un métal ont été formées sur 12 surface propre d'une pointe par la réaction d'une vapeur d'octacyanobenzène avec le métal de la polnte dans la chambre du microscope Ionique. Des inages avec de l'hydrogène ont été obtenues montrant la structure moléculaire de la phtalocyanine. Les Images de quelques molécules agregées parallèlement ont été aussi obtenues.

\section{Abstract}

Metal octacyanophthalocyanine molecules have been formed directly on a clean tip surfaces by in situ reaction of tip materials $(\mathrm{Ni}$ and $\mathrm{Fe}$ ) with ambient tetracyanobenzene vapor. FIM images with hydrogen which clearly show the molecular structure have been successfully obtained. Images of molecular clusters have also been obtained in which several molecules piled parallel.

\section{Introduction}

Attempts to observe organic molecules have been made with FEM, FIM and STM. Among many organic compounds, phthalocyanines are frequently chosen for the specimen because of their relatively low vapor pressures, good stability and characteristic four-fold symmetry which offer a good chance of inspection of molecular images. Indeed,



Fig.1. A reaction scheme of a formation of metal octacyanophthalocyanine $\left(M P C(C N)_{8}\right)$ from metals and tetracyanobenzene (TCNB). 
the orientations of phthalocyanine molecules in the crystals were often studied using molecular images obtained with TEM (1) and molecular images of chlorinated copper phthalocyanine molecules with atomic resolution were obtained with TEM(2).

Besides doublet- and doughnut-shaped images, four-leaf images reflecting the molecular structure were observed in the FEM studies $(3,4)$. Studies with STM on organic molecules have just set about and asymmetric four-lobe images of Cu-phthalocyanine molecules were reported (5). With FIM, however, the structured images have not yet been observed, although several efforts obtaining them have been made ( 6 ).

In the present study the specimens have been prepared not by a usually adopted method of vacuum deposition or deposition from a solution. Instead, $\mathrm{Ni}$ or Fe octacyanophthalocyanine $\left(\mathrm{Ni}\right.$ or $\operatorname{FePC}\left(\mathrm{CN}_{8}\right)$ molecules have been formed directly on tip surfaces by in situ reactions of tip materials with tetracyanobenzene (TCNB) vapor, according to the reaction scheme in Fig.1. Little impurity is expected at the interface of metal substrate and $M P C(C N)_{8}$ thus prepared.

\section{Experimental}

To avold deterioration of a channel plate and contaminations of inside walls of a metal FIM, NI or Fe tips were allowed to react with TCNB vapor in a glass FIM with greased ground joints, as shown in Fig. 2 .

$\mathrm{Ni}$ or Fe tips were imaged with hydrogen in the glass FIM with a background pressure lower than $10^{-5} \mathrm{~Pa}$. Then imaging gas was pumpers out and TCNB vapor was admitted to the chamber through a stopcock between the chamber and a side arm in which TCNB was placed. The pressure in the chamber was about $2 \times 10^{-3} \mathrm{~Pa}$ at room temperature. The $w$ loop on which a tip was welded was kept at about $400^{\circ} \mathrm{C}$ for 30 minutes by resistance heating. The temperature of the loop was

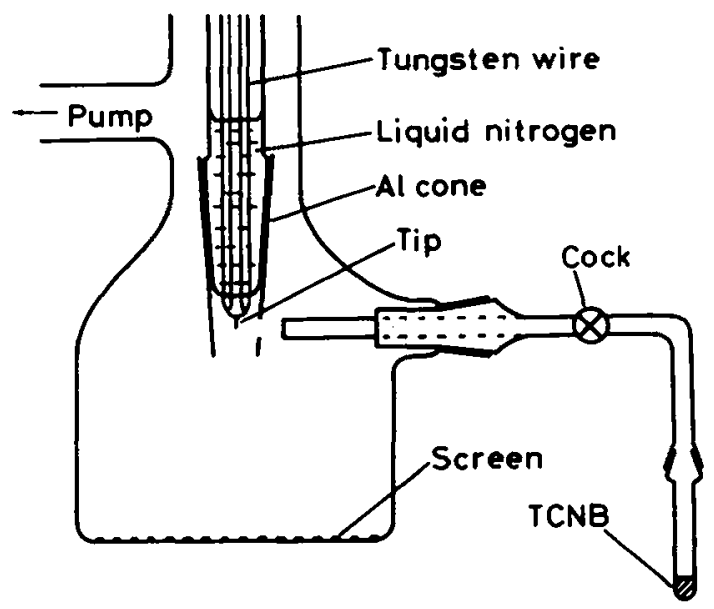

Fig.2. A schematic drawing of an FIM chamber for in situ reaction. TCNB is placed in a bottom of the side arm. 
monitored by four terminal method (7). The tip was then transferred through the air to the metal FIM equipped with a channel plate.

The metal FIM chamber was evacuated to 5 to $10 \times 10^{-7} \mathrm{~Pa}$ after baking the chamber at $200^{\circ} \mathrm{C}$ for 2 hours. Hydrogen ion images at $20 \mathrm{~K}$ were observed and taken photographs with the exposure time in between $1 / 4$ and 4 seconds.

\section{Results and discussion}

Images reflecting the molecular structure of $\mathrm{NiPC}(\mathrm{CN})_{8}$ were obtained from three tips among examined six tips.

A series of images of a $t i p$, which was allowed to react with TCNB vapor after it was field evaporated at $6.3 \mathrm{kV}$ in hydrogen at a pressure of $2 \times 10^{-2} \mathrm{~Pa}$, are shown in $\mathrm{F} I \mathrm{~g} .3$. As 1 maging voltage was gradually increased, broad spots appeared first and soon disappeared. Then Bright spots A through $H$ shown in Fig.3-a appeared. They changed their shapes and positions and occasionally disappeared as shown in Figs.3-a to $f$, although the imaging voltage was kept constant at $1.28 \mathrm{kV}$.

Pattern A was a $X$-shaped spot in Fig.3-a and changed its shape to a four-leaf form in Fig.3-b and disappeared during the exposure time of taking the photograph of Fig.3-c. Pattern B was a dim spot in Fig.3-a, changed its shape to an elongated spot in Fig.3-b and disappeared in Fig.3-d. Pattern $C$ was a large spot with two slightly dark area in Fig.3-a, an ellipsoidal single spot in Fig.3-b, a double spot in Fig.3-d and an elongated double spot in Figs3-d and $e$.

Pattern $D$ was an ellipsoidal single spot in Figs.3-a, b and $c$ and $a$ doughnut-shaped pattern in Fig.3-d. An additional four-leaf pattern appeared near the doughnut-shaped pattern in Fig.3-e. Pattern E and G remained single spots through the period they were observed, although their sizes changed. Pattern F was a single spot with gradation of brightness in Figs.3-a to $d$ and an additional dim double spot appeared in Fig.3-e. Pattern $H$ was a four-leaf form in Figs.3-a, $c$ and $d$ and $a$ single spot with gradations of brightness in Figs.3-b and $e$. All these images disappeared at a same time and then patterns $I$ and $J$ appeared as shown in Fig.3-f.

Pattern 1 showed three parallel dark stripes and pattern $J$ was double spot in Fig.3-f. These images were relatively stable. As the imaging voltage was increased to $1.47 \mathrm{kV}$, the orientation of pattern I varied. The gradation of brightness and number of dark stripes increased resulting in seven parallel elongated spots with dark region at their centers as shown in Fig.3-g. Pattern $J$ appeared as two double spots or a four-leaf form. After these patterns disappeared, several bright spots which changeds their shape and brightness appeared and soon disappeared.

As the imaging voltage was further increased, step rings of substrate $N i(111)$ began to appear. At this time many relatively bright spots were seen, but it was not clear whether these spots were 1 mages of $\mathrm{NiPc}(\mathrm{CN})_{8}$ or not. In the micrograph in Fig. 3-h after a first layer of Ni(111) plane was field evaporated, net $r$ ings of crystallographic planes except for the central (111) did not developed. They developed only after several tens of layers of the 




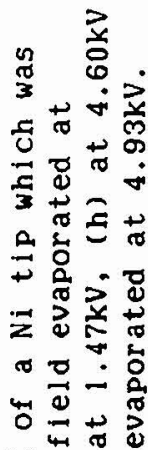
ํํำ

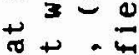
$0 \geq$

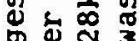
क 焉艺一 ธน ชี

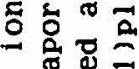
ㄷำ 号星二 记 로 岁声告 ข \&प्र

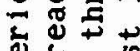
ब. ต 8.0 $\dot{0} \geq$ ज. 흥 iा 
central (111) plane were field evaporated.

Image patterns shown in Fig.3 and those of other tips frequently librated and changed their shapes and sizes. In the case when fourleaf pattern changed into single spots or double spots, they of ten resumed the original four-leaf form. Four-leaf patterns librated keeping their shapes. These features of the hydrogen ion images are quite similar to the images of ZnPc(1) and CuPc(2) observed with FEM, and clearly show that the images in Fig. 3 are molecular images of $\left.\mathrm{NiPC}_{\mathrm{PCN}}\right)_{8}$ Among them, patterns $A$ and $H$ in Fig.3 are images of a single molecule, whereas patterns C in Fig.3-a, D and F in Fig.3-e and $I$ in Figs.3-f and $g$ are images of clusters of several molecules.

It can be seen from image $I$ in Fig.3-g that a molecular cluster consists of several molecules which pile parallel to each other. These planar molecules are considered to stand on the substrate and parallel to each other. Neglecting a local distortion of a field, the separation between adjacent planar molecules may be estimated to about $3 A$ from the Image by taking account of the molecular size of NiPC(CN) to be nearly 15A. That value agrees well with that separation of 3.3 or $3.4 A$ in the $\alpha$-and $\beta$-polymorphs of various metal phthalocyanine crystals ( 8 ).

FIM images obtained in the present study certainly reflected a molecular structure. However, they are quite similar to FEM images and do not show atomic detalls of the molecule. It is considered that FIM images of these molecules with a conjugated $\pi$-electron system correspond to the molecular orbitals which concern the electron tunneling from Imaging gas molecules.

Similar observations were made with Fe tips allowed to react with TCNB vapor. Usually, FePc(CN) 8 molecules formed on tip surfaces were plentiful relative to $N i P C(C N) 8$ formed under the same condition and the images of FePc(CN $)_{8}$ changed their shapes and Ilbrated more violently than those of $\mathrm{NiPC}(\mathrm{CN})_{8}$ did. The four-leaf patterns of FePc(CN) 8 were particularly dim. Their photographs were diffcult to be taken. Some typical images of $\mathrm{FePc}(\mathrm{CN})_{8}$ are shown in Fig.4. The patterns indicated by arrows are four-leaf forms with a bright area at their center, although their feature of the image patterns are not clearly reproduced in the flgure, whereas four-leaf patterns of NiPC(CN) 8 lacked such a bright central area. These difference in the

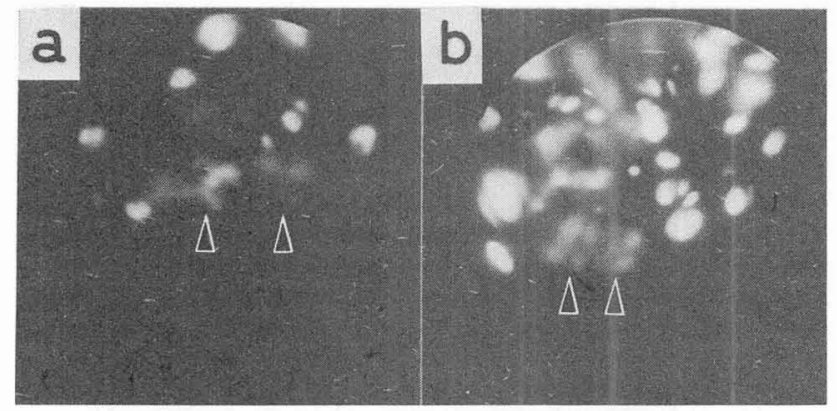

F19.4. Hydrogen images at $20 \mathrm{~K}$ of Fe tips which were allowed to react with TCNB vapor. (a) imaged at $1.03 \mathrm{kV}$, (b) at $1.40 \mathrm{kV}$. 
images with the difference of central metal atom may be interpreted in terms of the molecular orbitals concerned with the electron tunneling. In fact, the opening of a hole in low energy level in Fe in the MO dlagram for FePc was reported ( 9 ) but a full interpretation requires more detalled investigation.

Varlations of sizes and shapes of molecular images seem to be closely related to orientations and positions of molecules on the tip surfaces but must be discussed on the basis of more detailed characteristics of the images which should be investigated hereafter.

In the present study, field ion images which obviously reflect the structures of organic molecules have been obtained for the first time, although each atom is not resolved. Moreover, several kinds of orientations of molecules and molecular clusters were observed. Thus, possibilities of FIM observation of organic substances can be demonstrated. It is expected that the behavors of molecules on the metal surfaces and those of molecular clusters can be studied with FIM. The surface reactions of metal $\mathrm{Pc}(\mathrm{CN})_{8}$ formation may also be investigated in detail with FIM, concerning, e.g., reactivity dependence on metal species or on crystal planes.

Ref erences

1 T.Kobayashi, Y.Fujlyoshi, F.Iwatsu and N.Uyeda, Acta Cryst.,A37 (1987)692.

2 N.Uyeda, T.Kobayashi, K. Ishizuka and Y.Fujiyoshi, Chemica Scripta, 14(1978-1979)47.

3 R.Gomer and D.A.Speer, J.Chem.Phys., 21(1953)73.

4 A.J.Melmed and E.W.Müller, J.Chem.Phys., 29(1958)1037.

5 J.K.Gimzewski, E.Stoll and R.R.Schlittler,Surface Sci.,181 (1987)267.

6 e.g., E.W.Müller and K.d.Rendul ic, Science,156(1967)961; W.R.Graham, F.Hutchinson and D.A.Reed, J.Appl.Phys., 44(1973)5155.

7 H.Morikawa, M.Kozakai, T.Terao and Y.Yashiro, J.Vac.Sci.Technol., 21 (1982)95.

8 e.g., C.J.Brown, J.Chem.soc.A, (1968) 2488; R. Mason, G.A.will 1 ams and P.E.Fielding, J.Chem.Soc.Dal ton, (1979)676.

9 M.A.Schaffer, M.Gouterman and E.R.Davidson, Theoret.chim.Acta, 30 (1973)9. 